\title{
Effects of previous nutrition on the response to protein by weaner steers
}

\author{
SR McLennan 1, DP Poppi 2 \\ 1Dept Primary Industries, LMB No. 4, Moorooka, Qld 4105; 2Dept Agriculture, \\ University of Queensland, St Lucia, Qld 4072, Australia
}

Supplementation reduces liveweight loss in cattle grazing tropical pastures during the dry winter-spring period in northern Australia, but compensatory growth during the subsequent wet summer period often erodes much of this response. Using intra-gastric infused animals, Hovell et al (1978, Br J Nutr, 57, 77-88) showed enhanced nitrogen retention and higher protein requirements in lambs exhibiting compensatory growth. It may be possible, therefore, to exploit this compensatory growth by increasing protein intake during the summer.

An experiment was conducted in which 52 weaner Bos indicus crossbred steers (liveweight $145 \mathrm{~kg}$ ) were initially fed for $60 \mathrm{~d}$ in pens a basal diet of low quality tropical native pasture hay $(0.4 \% \mathrm{~N})$, either without supplement (control, $C$ ) or with $500 \mathrm{~g} / \mathrm{d}$ cottonseed meal $(P)$. During this phase, control animals lost $8 \mathrm{~kg}$ and $P$ animals gained $10 \mathrm{~kg}$ liveweight. Animals within original groups were then re-allocated and the steers were given Rhodes grass hay $(1.0 \% \mathrm{~N})$ with increasing levels of cottonseed meal $(7.8 \% N)$. Liveweight changes over a $60 \mathrm{~d}$ pen feeding period are shown in the table.
Previous nutrition had no effect on the response to protein supplement in the second phase, or apparently on protein requirements. It appears that the initial growth rates, although representative of those often encountered under grazing conditions, were not sufficiently different to elicit differences in the response relationships to protein supplement. Further investigation is required covering a wider range of growth rates during the restriction period. There was a sharp increase in growth rate to the first increment of supplement, probably reflecting correction of a deficiency of rumen degradable nitrogen for microbial growth. Subsequent increments in cottonseed meal resulted in a linear liveweight response which did not peak at even the highest intake. When estimated ME intake was plotted against estimated energy retention based on liveweight gain, the $k_{f}$ value was 0.50 . Thus the protein response occurred within the normal range of $k_{f}$ values for such diets. In conclusion, the results suggest that higher levels of supplementation than are currently recommended may be appropriate.
Cottonseed meal intake $(\mathrm{kg} / \mathrm{d})$

$$
0
$$

0.50

0.75

1.00

1.25

1.50
Liveweight change $(\mathrm{kg} / \mathrm{d})$

$\begin{array}{cc}C & P \\ 0.10 & 0.13 \\ 0.46 & 0.49 \\ 0.56 & 0.58 \\ 0.70 & 0.64 \\ 0.73 & 0.80 \\ - & 0.86 \\ 0.95 & 0.95\end{array}$

